\title{
Passage and rumination of inert particles varying in size and specific gravity as determined from analysis of faecal appearance using multicompartment models
}

\author{
BY M. R. MURPHY*, P. M. KENNEDY $\ddagger$ AND J. G. WELCH $\dagger$ \\ CSIRO Division of Tropical Animal Production, Davies Laboratory, Private Mail Bag, Aitkenvale, \\ Queensland 4814, Australia
}

(Received 8 February 1988 - Accepted 2 May 1989)

\begin{abstract}
Plastic particles of defined length $(2,5 \mathrm{~mm})$ and specific gravity (sp.gr. 1.10, 1.34, 1.77) were administered just before feeding into the reticulo-rumen of four cattle and four swamp buffaloes given a diet predominantly of rice straw ad lib. Simultaneously, doses of ground rice straw marked with $\mathrm{Cr}$ and Yb were likewise given. Plastic particles were recovered from faeces for $12 \mathrm{~d}$ after dosing, and divided into non-ruminated (NR) and ruminated (R) particles. Excretion data of plastic particles were interpreted using a four-pool model incorporating passage of NR $\left(k_{\mathrm{p}}\right)$ and $\mathrm{R}$ from the reticulo-rumen, post-ruminal passage, rate of chewing $\left(k_{\mathrm{r}}\right)$ and two lag times. An inverse relationship was found between $k_{\mathrm{r}}$ and sp.gr. The $k_{\mathrm{r}}$ was higher for $5 \mathrm{~mm}$ than that for $2 \mathrm{~mm}$ particles. In contrast, $k_{\mathrm{p}}$ was greatest for particles of sp.gr. 1.34, with higher $k_{\mathrm{p}}$ for $2 \mathrm{~mm}$ than for $5 \mathrm{~mm}$ particles. Rates of passage and rumination $\left(k_{\mathrm{p}}, k_{\mathrm{r}}\right)$ were higher for buffaloes than for cattle. Rumination time was related to $k_{\mathrm{r}}$, most highly $\left(r^{2} 0.96\right)$ with $k_{\mathrm{r}}$ of $2 \mathrm{~mm}, 1 \cdot 10 \mathrm{sp} . g r$. particles. Fragmentation of $5 \mathrm{~mm}$ particles by rumination tended to increase the rate of passage from the rumen. Ruminal passage rates of $\mathrm{Yb}$ and $\mathrm{Cr}$ markers were poorly correlated with each other and with $k_{\mathrm{p}}$ of any of the plastic markers. Reanalysis of published data from plastic particle studies supported the relationships between sp.gr., size, $k_{\mathrm{p}}$ and $k_{\mathrm{r}}$. In view of the additional information $\left(k_{r}\right)$ obtained using plastic particles, we suggest their use may be appropriate in studies which investigate specific differences in digestive function, while being less suitable for investigating differences between diets.
\end{abstract}

Plastic particle markers: Rumination rates: Specific gravity: Cow : Buffalo

Studies of ruminant digestion often include determination of mean retention time of particulate material in the rumen in order to calculate the amount of digestion from the rate of digestion, commonly estimated using the synthetic fibre bag technique. Mean retention time is estimated by dosing with particulate markers and either following their disappearance from the rumen or their appearance in the faeces. However, available markers suffer from non-ideal properties (Warner, 1981) such as migration between particles, variable inhibition of microbial activity (Evans et al. 1977) and variations in properties of size and specific gravity (sp.gr.) which may reduce their ability to move with digesta. Various inert materials have been used to study the effects of particle size and specific gravity on passage (King \& Moore, 1957; Campling \& Freer, 1962; desBordes \& Welch, 1984); however, there has not been enough information available from which to recommend a size and sp.gr. combination that mimics passage of digesta particles from the rumen. As part of a study of factors which affect roughage intake, we wished to investigate whether the reputed superior ability of a ruminant species (swamp buffalo) to utilize fibrous diets was reflected in differences in passage behaviour of plastic particles of defined length

Present addresses: * Department of Animal Sciences, University of Illinois, Urbana, IL 61801, USA.

$\dagger$ Department of Animal Science, University of Vermont, Burlington, VT 05405, USA.

$\ddagger$ For reprints. 
and sp.gr. through the gut. In particular, we wished to determine the relative efficiency of chewing during rumination by swamp buffalo and cattle, in view of the proposed importance of rumination in the removal of undigested fibre from the rumen (e.g. Welch, 1986).

Plastic particles recovered from faeces after intra-ruminal dosing can be separated into ruminated and non-ruminated fractions based on the presence or absence of teeth marks respectively (desBordes \& Welch, 1984). This characteristic provided an opportunity to obtain data about mechanisms involved in selecting particles for rumination and regulating digesta passage from the reticulo-rumen, important areas needing more quantitative information (Reid, 1984). Fractional passage rate (FPR) of digesta from the rumen is considered a major determinant of both digestion in this compartment and voluntary feed consumption.

\section{MATERIALS AND METHODS}

Four castrate male swamp buffaloes and four ovariectomized zebu crossbred cattle, aged 2.5 years, weighing $225-280 \mathrm{~kg}$ and equipped with simple rumen and simple abomasal fistulae, were fed ad lib. on a mixture $(95: 5, \mathrm{w} / \mathrm{w}$ ) of rice straw (Oryza sativa, $660 \mathrm{~g}$ cell wall constituents (CWC, method of Van Soest \& Wine, 1967) and $4.6 \mathrm{~g} \mathrm{~N} / \mathrm{kg}$ dry matter (DM)) and leucaena leaf (Leucaena leucocephala, $398 \mathrm{~g} \mathrm{CWC}$ and $34 \cdot 1 \mathrm{~g} \mathrm{~N} / \mathrm{kg} \mathrm{DM}$ ), together with a mineral mix $(100 \mathrm{~g} / \mathrm{d}$, Siebert \& Kennedy, 1972). Feed was offered once daily at 1.2 times consumption during the previous day. After 2 weeks of adaptation to the diet, doses $(4000$ particles, $1 \cdot 0-1 \cdot 3 \mathrm{~mm}$ diameter cylinders) of colour-coded plastic particles of three specific gravities $(1 \cdot 10,1 \cdot 34,1.77 \mathrm{sp} . g r$. $)$ and two lengths $(2$ or $5 \mathrm{~mm})$ were administered into the ventral rumen at 08.00 hours; i.e. just before fresh feed was given. In addition, animals were dosed with labelled feed particles of rice straw which had been previously ground through a $1 \mathrm{~mm}$ screen and extracted with sodium lauryl sulphate $\left(100^{\circ}, 18 \mathrm{~h}\right)$. Particles were labelled by immersion in a solution of hydrated $\mathrm{Yb}$-acetate $(100 \mathrm{~g} / \mathrm{l}$, Research Chemicals, Phoenix, Arizona, USA) at pH 5.5 and washed as described by Mader et al. (1984), or were mordanted with $\mathrm{Cr}$ as described by Uden et al. (1980).

Jaw movements were detected by the extension of an electrically semi-conductive silicone rubber tube placed under the jaw of the animal (see Penning, 1983).

The functional sp.gr. of labelled materials was measured in pycnometers as described by Hooper \& Welch (1985); fibre labelled with Yb had a sp.gr. of 1.56 whereas that labelled with $\mathrm{Cr}$ was 1.37. Measured by an adaptation of the technique of Evans et al. (1973) of density gradient centrifugation in a linear ethanol to carbon tetrachloride mixture $\left(10000 \mathrm{~g}, 15 \mathrm{~min}, 4^{\circ}\right)$, their sp.gr. was $>1.47$ and $>1.50$ respectively. The poor agreement between techniques for particles labelled with $\mathrm{Cr}$ was attributed to greater displacement by ethanol/ $\mathrm{CCl}_{4}$ of gas trapped within the fibre matrix.

Faeces were collected quantitatively at intervals of $12 \mathrm{~h}$ for $5 \mathrm{~d}$, thereafter at $24 \mathrm{~h}$ intervals for $7 \mathrm{~d}$. After subsampling (1-3\% of total) faeces for $\mathrm{Yb}$ and $\mathrm{Cr}$ analysis, plastic particles were recovered by hosing remaining faeces through a large screen, followed by separation of the dried residue using a vibrating seed separator. Particles were identified, counted, and separated manually into non-ruminated (NR) and ruminated (R) particles, according to the absence or presence of teeth marks. Recovery of particles broken during rumination was determined by weighing the resulting fragments.

$\mathrm{Cr}$ in faeces was analysed by the method of Williams et al. (1962). Yb concentration was determined by the method of Hart \& Polan (1984) with use of a carbon furnace and detection by atomic emission.

Least-squares estimates of model parameters were made using the 1981 version of a 


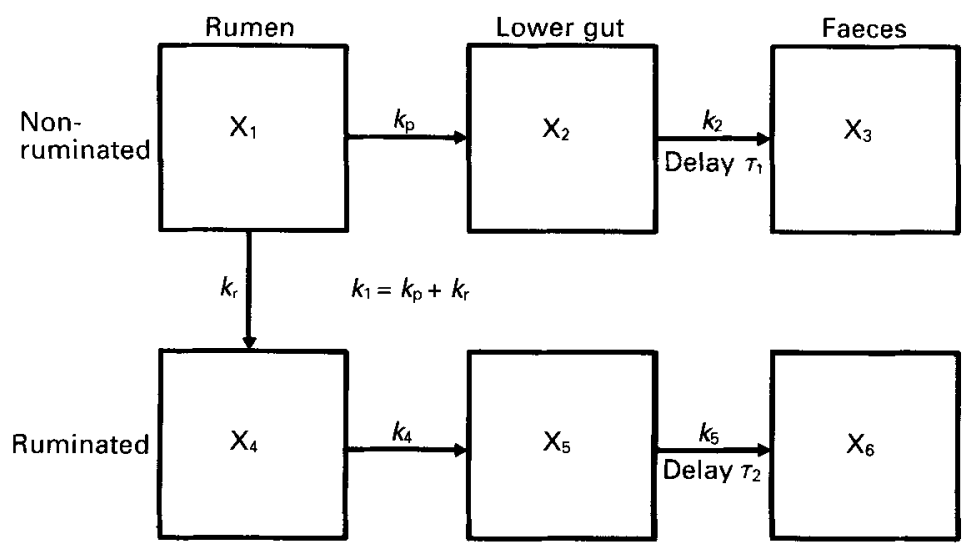

Fig. 1. Model chosen to represent rumination and passage of non-ruminated and ruminated plastic particles varying in specific gravity and length.

derivative-free non-linear regression technique (Ralston, 1979). The program was implemented on a DEC System-10 computer.

\section{Choice of model}

Passage and rumination of NR particles was envisaged as analogous to a three compartment model $\left(X_{1}, X_{2}\right.$ and $\left.X_{3}\right)$ containing an accumulation compartment, as described by Atkins (1969) but with a discrete lag between the last two pools (Blaxter $e t$ al. 1956; Grovum \& Williams, 1973; see Fig. 1). The model, shown in the top half of Fig. 1, was fitted to $\ln$ (faecal concentration of NR particles) $v$. time data to estimate $k_{1}, k_{2}$ (the fractional passage rate of NR particles from the lower gut) and $\tau_{1}$. In this scheme, rate constant $k_{1}$ of the pool as a whole actually represented the sum of $k_{\mathrm{p}}$ (the fractional passage rate of NR particles) and $k_{\mathrm{r}}$ (the fractional rumination rate of NR particles) since these were the only possible routes of exit from the pool. By fitting in (concentration) it was possible to stabilize the variance and obtain a uniform distribution of residuals similar to that described by Dhanoa et al. (1985). The fact that cumulative faecal output of NR particles reached a plateau by $12 \mathrm{~d}$ postdosing allowed $k_{\mathrm{p}}$ and $k_{\mathrm{r}}$ to be determined based on the assumption that only $\mathrm{R}$ particles would appear after that time; i.e. since flow of $\mathrm{NR}=k_{\mathrm{p}} \times$ pool and total flow $=k_{1} \times$ pool, then $k_{\mathrm{p}} / k_{1}$ was equated to the ultimate recovery of NR as a proportion of the dose. An underlying assumption of our proposed model was that NR particles selected for passage or rumination can be considered to be from the same pool, or from subpools in rapid equilibrium compared with the time for appreciable passage or rumination. From available information and given the relatively frequent mixing contractions of the reticulo-rumen, the latter concept is more defensible. Recently, Dardillat (1987) suggested that both resting and rumination contractions are associated with forward and backward movement of digesta through the reticulo-omasal orifice. Accordingly, regurgitated and passed digesta may conceivably be selected from the same pool. Passage of $\mathrm{R}$ particles was viewed as a four compartment model $\left(X_{1}, X_{4}, X_{5}\right.$ and $\left.X_{6}\right)$, also with an accumulation compartment and discrete lag between the last two pools; however, prior estimation of $k_{1}$ for NR particles meant that only $k_{4}$ (the fractional passage rate of $\mathrm{R}$ particles from the rumen), $k_{5}$ (the fractional passage rate of $\mathrm{R}$ particles from the lower gut) and $\tau_{2}$ needed to be determined using $\ln$ (faecal concentration of $\mathrm{R}$ particles) over time data. 


\section{RESULTS}

\section{Faecal appearance of plastic particles}

Cumulative recoveries of NR and R particles are summarized for each species in Tables 1 and 2, respectively. Recovery of $2 \mathrm{~mm}$ particles (NR plus $\mathrm{R}$ ) from cattle over $12 \mathrm{~d}$ declined from 80 to $72 \%$ of particles dosed, as sp.gr. increased from $1 \cdot 10$ to $1 \cdot 77$, but recovery for buffaloes increased from $82 \%$ of dose to $91 \%$. In contrast, recovery of $5 \mathrm{~mm}$ (NR plus R) particles was poor $(26-36 \%)$ for $1 \cdot 10$ sp.gr. but increased to $63-89 \%$ for the heavier particles. Plateau excretion of NR $2 \mathrm{~mm}$ particles was reached earlier for buffaloes than for cattle, with recovery after $12 \mathrm{~d}$ from buffaloes achieving 75, 93 and $148 \%$ of cattle values for $1 \cdot 10,1.34$ and $1.77 \mathrm{sp}$.gr. (Table 1). After $12 \mathrm{~d}$, fewer $5 \mathrm{~mm}$ than $2 \mathrm{~mm}$ particles were recovered unruminated, with the differences being inversely related to specific gravity.

Buffaloes excreted more $R$ particles than did cattle (Table 2). There was an inverse relationship between proportion of the dose excreted over $12 \mathrm{~d}$ and specific gravity of $2 \mathrm{~mm}$ particles, but the relationship was curvilinear for $5 \mathrm{~mm}$ particles. The collection period of $12 \mathrm{~d}$ was insufficient to achieve plateau excretion of $R$ particles except for $2 \mathrm{~mm}, 1.34$ sp.gr. particles in buffaloes.

\section{Fractional rates of passage and rumination}

Estimates of $k_{\mathrm{p}}$ and $k_{\mathrm{r}}$ for each sp.gr. and length combination were obtained for all buffaloes but for only two of the four cattle. Low recovery of particles was associated with an inability to derive rate constants. Recovery of NR particles of $1.77 \mathrm{sp}$.gr. after $12 \mathrm{~d}$ was close to, but not at, plateau. To the extent that NR had not reached plateau, the estimate of $k_{\mathrm{p}}$ would be underestimated, and $k_{\mathrm{r}}$ overestimated to the same extent, without affecting the derived value for $k_{1}$. For both species and particle lengths, maximum values of $k_{\mathrm{p}}$ and $k_{\mathrm{r}}$ occurred at 1.34 and $1.10 \mathrm{sp}$.gr. respectively (Fig. 2a,b). Time (mean (SEM)) spent ruminating by buffaloes and cattle (635 (SEM 24) v. 452 (SEM 15) min/d respectively; McSweeney \& Kennedy, 1987) was closely correlated with $k_{\mathrm{r}}$ for $2 \mathrm{~mm} 1 \cdot 10$ sp.gr. particles $(r 0.98 ; P<0.01)$; when $k_{r}$ was expressed on the basis of rumination time, the rate at which teeth marks appeared on these particles was 0.070 (SEM 0.0022) v. 0.105 (SEM 0.0015) per $h$ of rumination for cattle and buffaloes respectively. Time spent ruminating was also correlated with $k_{\mathrm{r}}$ for $2 \mathrm{~mm} 1.34 \mathrm{sp}$.gr., and $5 \mathrm{~mm} \mathrm{l} 10$ sp.gr. particles, if values from one buffalo were excluded $\left(r^{2} 0.67,0.69\right.$ respectively, $\left.P<0.05\right)$. Apparently, this buffalo was unable to ruminate efficiently the latter particles, and during a subsequent period of restricted intake, produced $43 \%$ fewer fine digesta particles (those passing a screen with $150 \mu \mathrm{m}$ pores) per minute of rumination (Kennedy et al. 1987).

The mean (SEM) $k_{1}$ for Yb-labelled particles was 0.033 (SEM 0.0019)/ $\mathrm{h}$ in cattle and 0.044 (SEM 0.0047 ) $/ \mathrm{h}$ for buffaloes $\left(P>0.05\right.$ ). For $\mathrm{Cr}$-mordanted fibre, $k_{1}$ averaged 0.020 (SEM $0.0005) / \mathrm{h}$ and 0.023 (SEM 0.0006$) / \mathrm{h}$ in cattle and buffaloes respectively $(P<0.05$ ). FPR (i.e. $k_{1}$ values) of the two markers were not significantly correlated with each other or to $k_{\mathrm{p}}$ for any of the plastic markers but that for Yb-particles was correlated $\left(r^{2} 0.75 ; P<0.05\right)$ with duration of rumination.

Ruminal FPR (i.e. $k_{\mathrm{p}}$ ) in buffaloes were higher by 40,76 and $216 \%$ respectively for $2 \mathrm{~mm}$ particles of sp.gr. $1 \cdot 10,1.34$ and 1.77 compared with cattle. Across species, $k_{\mathrm{p}}$ was poorly related to rumination time $\left(r^{2} 0.02\right.$ to 0.30$)$. On average $k_{\mathrm{p}}$ for $2 \mathrm{~mm}$ particles was $2 \cdot 2$ times $k_{\mathrm{p}}$ for $5 \mathrm{~mm}$ particles, with the latter being similar between species. The $k_{4}$ of $\mathrm{R}$ relative to $k_{\mathrm{p}}$ of NR $2 \mathrm{~mm}$ particles was dependent on sp.gr., with a ratio of $\mathrm{R}: \mathrm{NR}$ of 0.77 (SEM 0.07): $1,0.97$ (SEM 0.15): 1 and 1.31 (SEM 0.29): 1 for particles of sp.gr. 1.1, 1.34 and 1.77 respectively. In contrast, for $5 \mathrm{~mm}$ particles, which fragmented during chewing, rumination tended to increase passage rate from the rumen by 55 to $145 \%$, with the increase largely 


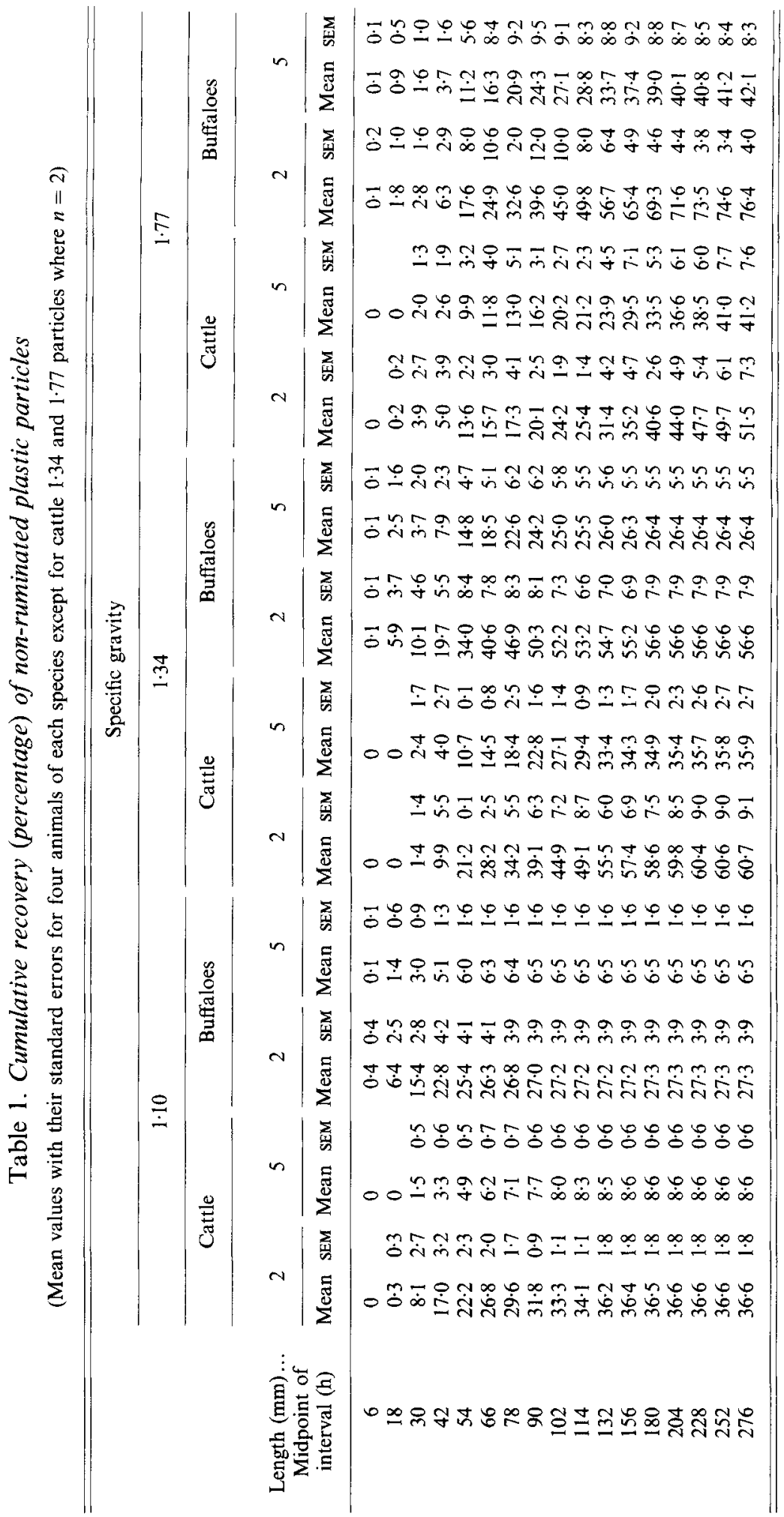




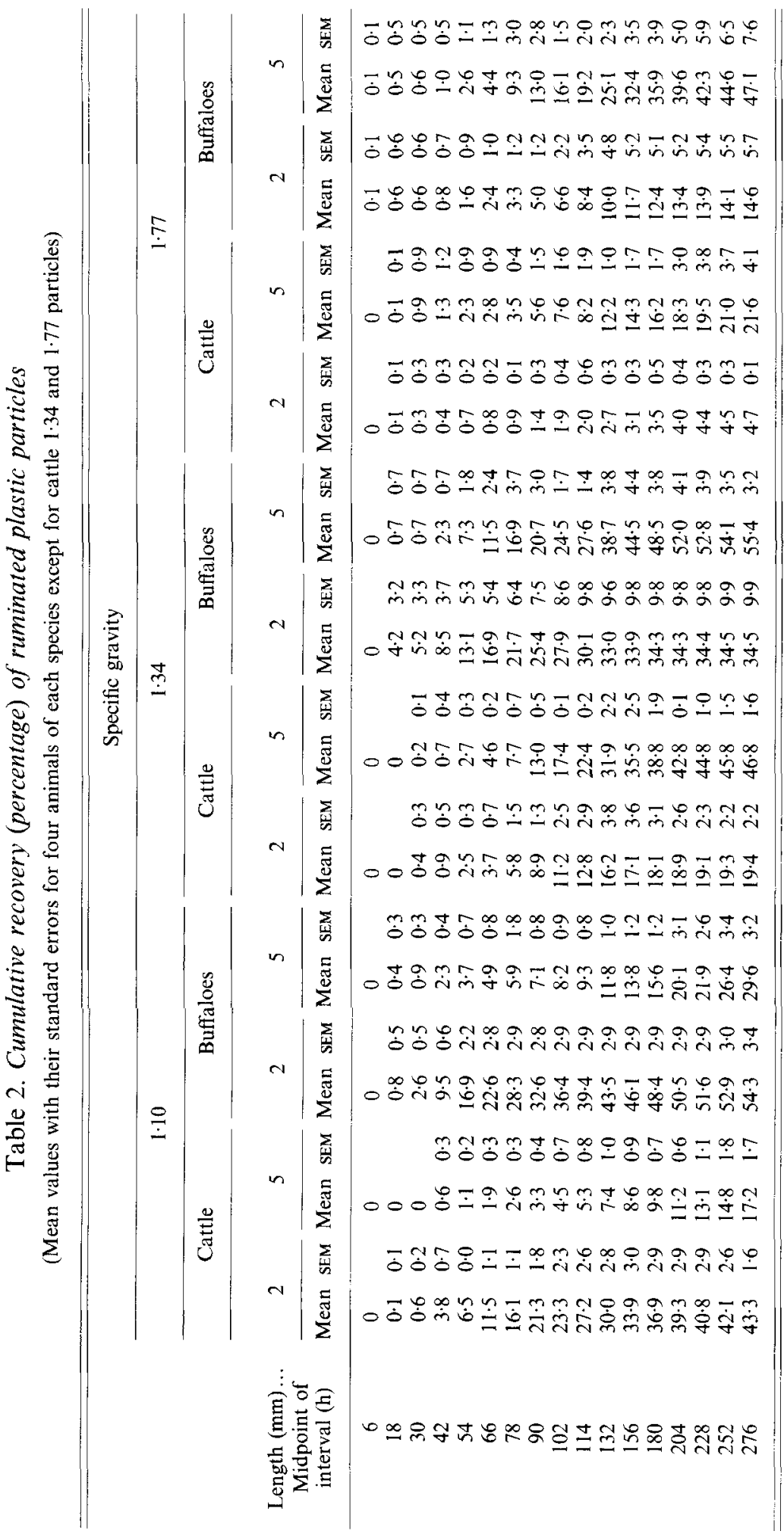

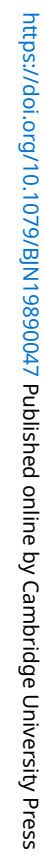




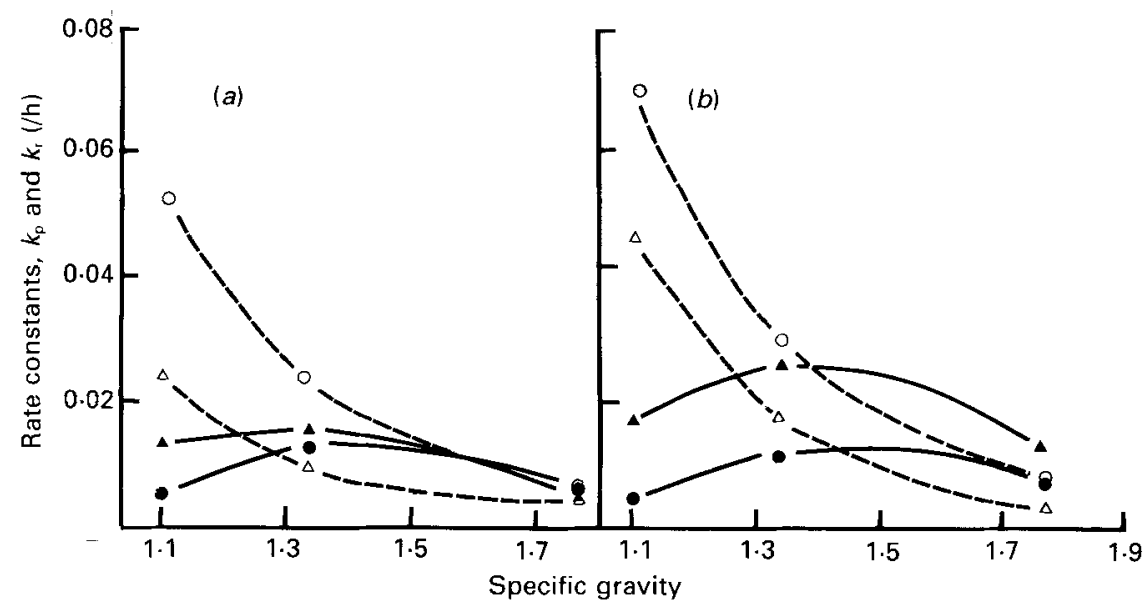

Fig. 2. Rates of rumination $\left(k_{\mathrm{r}}: 5 \mathrm{~mm}, \bigcirc ; 2 \mathrm{~mm}, \Delta\right)$ and passage from the rumen $\left(k_{\mathrm{p}}: 5 \mathrm{~mm}, \boldsymbol{O} ; 2 \mathrm{~mm}, \Delta\right)$ as affected by specific gravity and length of plastic particles $(2$ and $5 \mathrm{~mm})$ in cattle $(a)$ and buffaloes $(b)$.

Table 3. Correlation of rates of passage from the rumen $\left(\mathrm{k}_{p}\right)$ for plastic particles varying in specific gravity and length

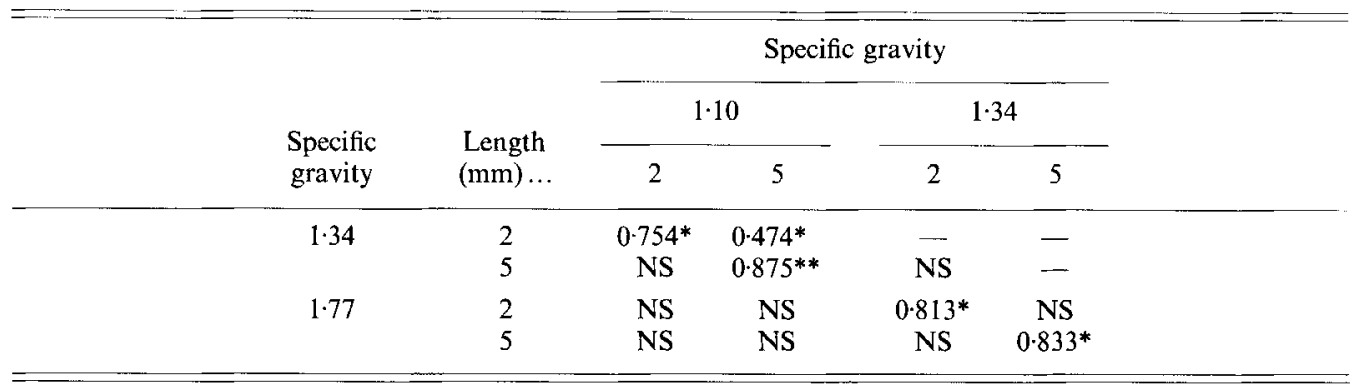

NS, not significant.

$* P<0.05 ; * * P<0.01$.

attributable to size reduction of the plastic marker. Correlations between $k_{\mathrm{p}}$ of particles differing in sp.gr. and size indicated that there was more consistency of movement of particles of the same size regardless of sp.gr. than of particles of the same sp.gr. regardless of size (Table 3).

Post-ruminal FPR for NR $\left(k_{2}\right)$ and $\mathrm{R}\left(k_{5}\right)$ particles were similar $(P>0.9)$, averaging 0.044 (SEM 0.005) and 0.048 (SEM 0.008) $(n$ 10) across species and lengths at a sp.gr. of 1.34. For other sp.gr., direct comparison was precluded by variation in $k_{2}$ and $k_{5}$, which resulted from poor definition of the early segment of faecal appearance curves due to relatively infrequent sampling.

\section{DISCUSSION}

Use of compartmental models to describe the flow of substances through the digestive tract of animals has been reviewed recently (France et al. 1985). It was concluded that the double-exponential model proposed by Dhanoa et al. (1985) appeared to have a wide range of practical applications. In its partly linearized form, obtained by logarithmic 


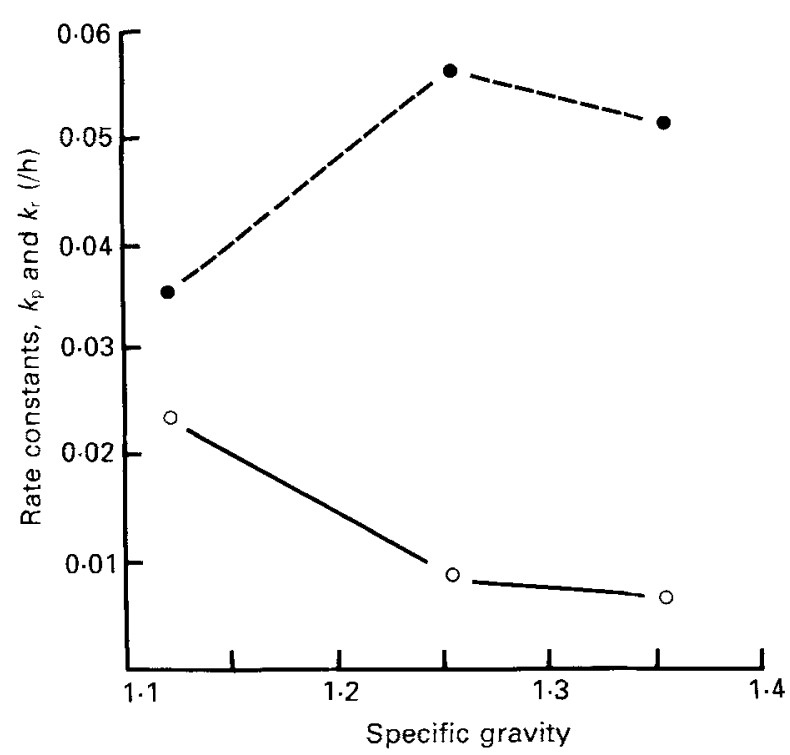

Fig. 3. Rates of rumination $\left(k_{r}, O\right)$ and passage from the rumen $\left(k_{n}, \boldsymbol{O}\right)$ across particle length as affected by specific gravity of plastic particles for the data of Durkwa (1983).

transformation, this model was found by these authors to be particularly effective in describing digesta flow along the gastrointestinal tract of ruminants. However in view of (i) the simplified kinetics of plastic particle movement compared with rumen digesta which undergoes time-dependent changes in sp.gr. and size and (ii) differences in estimates of $k_{2}$ (attributable to marker excretion from the post-ruminal pool) derived from use of alternative models (Dhanoa et al. 1985; Beauchemin \& Buchanan-Smith, 1987) we have described passage and rumination of plastic particles by reference to a simple threecompartment model with a discrete lag between the last two pools (Blaxter et al. 1956; Grovum \& Williams, 1973).

The patterns of $k_{\mathrm{p}}$ and $k_{\mathrm{r}}$ with sp.gr. showed that maximum rates of rumination occurred at a lower sp.gr. than did maximum passage from the reticulo-rumen. Similar patterns were evident when the data of Durkwa (1983) and desBordes \& Welch (1984) were reanalysed using the model shown in Fig. 1 (Figs 3 and 4). In addition, particle length affected $k_{\mathrm{p}}$ and $k_{\mathrm{r}}$ in cows (results of Durkwa, 1983; Fig. 5) with the major effects evident for particles $5 \mathrm{~mm}$ or greater in length. These findings are consistent with concepts of the importance of size and sp.gr. in contributing to the sorting of particles in the reticulo-rumen into dense small particles which tend to flow to the omasum and lighter, longer particles which tend to be aspirated into the mouth during rumination (Wyburn, 1980).

There was an apparent association of the greater force of reticular contractions of swamp buffaloes (McSweeney \& Kennedy, 1987) with increased $k_{\mathrm{p}}$ of the $2 \mathrm{~mm}$ relative to $5 \mathrm{~mm}$ plastic particles. At the same time, retention of large plastic particles in the buffalo rumen was reduced by more prolonged rumination and higher $k_{\mathrm{r}}$. In addition, in both cattle and buffaloes, data for NR $\left(k_{\mathrm{p}}\right)$ and $\mathrm{R}\left(k_{4}\right), 2 \mathrm{~mm}$ plastic particles indicated that the passage from the reticulo-rumen of heavy ( $>1.4$ sp.gr.) particles was enhanced by rumination activity. This presumably resulted from dispersal of light particles away from the reticuloomasal orifice after reswallowing of the chewed bolus, and would function in preferentially removing from the rumen digesta particles which had undergone extended digestion. For 


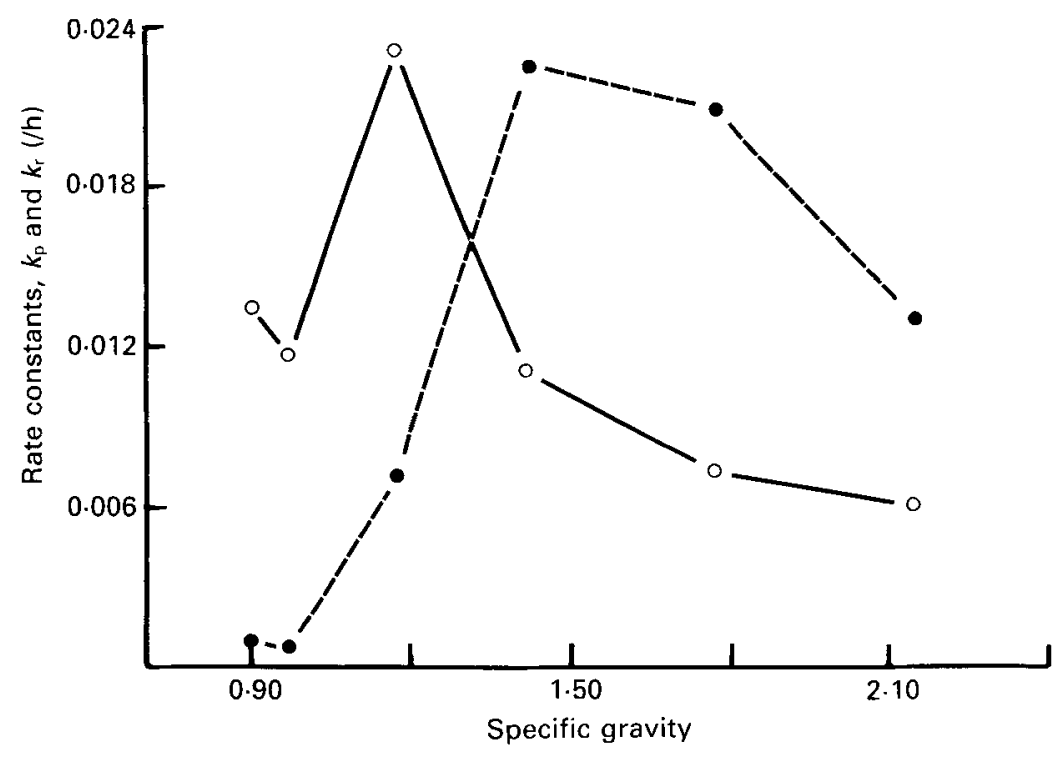

Fig. 4. Rates of rumination $\left(k_{\mathrm{r}}, O\right)$ and passage from the rumen $\left(k_{1}, O\right)$ as affected by specific gravity of plastic particles for the data of desBordes \& Welch (1984).

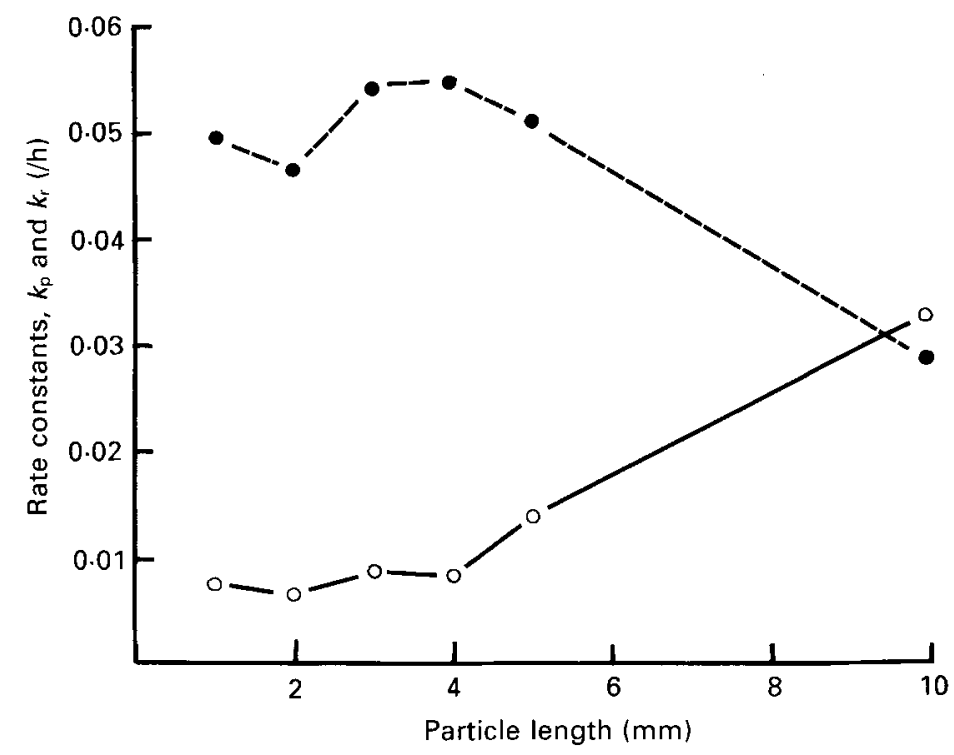

Fig. 5. Rates of rumination $\left(k_{\mathrm{r}}, \bigcirc\right)$ and passage from the rumen $\left(k_{\mathrm{p}}, \boldsymbol{O}\right)$ across specific gravity as affected by length of plastic particles for the data of Durkwa (1983).

swamp buffaloes given the rice straw-based diet used in the present experiment, the reduced time available for action of cellulolytic microbes depressed digestibility of cell wall constituents, but the consequent depression in digestible organic matter intake was compensated for by increased feed intake (Kennedy et al. 1987).

The effects of sp.gr. on the fate of particles in the reticulo-rumen is pertinent to the 
accuracy with which markers adherent to particles requiring pretreatment with detergent to remove cell solubles may mimic the passage of digesta to the intestines. The poor correlations between FPR for Yb-labelled and Cr-mordanted fibre, and $k_{\mathrm{p}}$ of plastic particles indicates that such markers yield FPR estimates which may be of limited value. Others (Mader et al. 1984; Coleman et al. 1984; Smith et al. 1987; Cochran et al. 1987) have also reported that material labelled with $\mathrm{Yb}$ passed from the rumen quicker than that labelled with $\mathrm{Cr}$; however, none have stated whether or not measurements within individual animals were correlated. Poncet \& Al Abd (1984) explained differences between mean retention times in sheep of $\mathrm{Cr}$-mordanted fibre and $\mathrm{Yb}$ marker as the result of altered digestion of the former, and adherence of the latter to the small particle fraction of rumen digesta. Moreover, Smith et al. (1987) found that fluid dilution in vitro influenced fractional passage rates of $\mathrm{Cr}$ and $\mathrm{Yb}$ markers. The fact that $\mathrm{Yb}$ - and $\mathrm{Cr}$-labelled materials had such high sp.gr. in our experiment may have influenced their propensity to be comminuted during rumination and their FPR from the rumen. In addition, the effect of rumination in acceleration of passage of chewed relative to non-ruminated material of sp.gr. $>1.4$ may differentially affect dietary residues labelled with $\mathrm{Yb}$ or $\mathrm{Cr}$. The bulk density of $\mathrm{Cr}$ mordanted material has been shown to affect its FPR (Ehle et al. 1984). Although relative treatment comparisons may still be valid, the above results do not engender confidence in the accuracy with which these markers estimate FPR.

The agreement in FPR ( $k_{2}$ and $k_{5}$, respectively) in the post-ruminal tract of NR and R particles is consistent with the conclusion of Siciliano-Jones \& Murphy (1986) that length of inert particles, from 1 to $10 \mathrm{~mm}$, did not affect post-ruminal passage in steers. Others (King \& Moore, 1957; Campling \& Freer, 1962; Siciliano-Jones \& Murphy, 1986) have reported post-ruminal passage rate was maximized with particles having a sp.gr. of approximately 1.2; however, Campling \& Freer (1962) found that the fractional passage rate of inert particles in the lower gut was inversely related to sp.gr. and slower than that from the reticulo-rumen within the range $1 \cdot 12$ to 1.40 . Over this range the common assumption that the slowest FPR applies to the reticulo-rumen may be incorrect. To identify compartments correctly, Faichney \& Boston (1983) suggested that liquid and particulate phase markers be used simultaneously (when unable to sample directly from the rumen) because these phases do not behave independently in the lower gut of ruminants. Although the closeness of $k_{1}$ (equal to $k_{\mathrm{r}}+k_{\mathrm{p}}$ ) and $k_{2}$ at a sp.gr. of 1.34 made these parameters computationally difficult to estimate in our study (see Atkins, 1969), it also made compartment identification less critical. Had the fractional passage rates differed substantially, it would have been difficult to assign them to a particular compartment without additional information.

Use of plastic particles of defined sp.gr. and length, although laborious, has yielded information concerning effectiveness of rumination and passage which is not available using other markers, and combined with estimates of digesta particle size, rumen fill and intake, offers the possibility of examining the differences between animals and species in their ability to utilize roughage diets. For the two large ruminant species used in this study, use of the plastic markers allowed us to conclude that faster passage of digesta through the reticulo-rumen of the swamp buffalo was attributable to more prolonged (and perhaps more efficient) rumination in conjunction with more effective propulsion of small digesta particles to the intestines.

Michael R. Murphy acknowledges the receipt of partial support from CSIRO (Australia). Drs A. John and A. Schlink assisted with collection and harvesting of plastic particles from the animals. 


\section{REFERENCES}

Atkins, G. L. (1969). Multicompartment Models for Biological Systems. London: Methuen.

Beauchemin, K. A. \& Buchanan-Smith, J. G. (1987). Evaluation of markers, sampling sites and models for estimating rates of passage of silage or hay. Journal of Dairy Science 70, Suppl. 1, 193.

Blaxter, K. L., Graham, N. McC. \& Wainman, F. W. (1956). Some observations on the digestibility of food by sheep, and on related problems. British Journal of Nutrition 10, 69-91.

Campling, R. C. \& Freer, M. (1962). The effect of specific gravity and size on the mean time of retention of inert particles in the alimentary tract of the cow. British Journal of Nutrition 16, 507-518.

Cochran, R. C., Adams, D. C., Galyean, M. L. \& Wallace, J. D. (1987). Examination of methods for estimating rate of passage in grazing steers. Journal of Range Management 40, 105-108.

Coleman, S. W., Evans, B. C. \& Horn, G. W. (1984). Some factors influencing estimates of digesta turnover rate using markers. Journal of Animal Science 58, 979-986.

Dardillat, C. L. (1987). Débit réticulo omasal instantané chez la vache (Instantaneous reticulo omasal flow in the calf.) Reproduction, Nutrition, Développement 27, 231-232.

desBordes, C. K. \& Welch, J. G. (1984). Influence of specific gravity on rumination and passage of indigestible particles. Journal of Animal Science 59, 470-475.

Dhanoa, M. S., Siddons, R. C., France, J. \& Gale, D. L. (1985). A multicompartmental model to describe marker excretion patterns in ruminant faeces. British Journal of Nutrition 53, 663-671.

Durkwa, L. M. (1983). Length and specific gravity of particles passed from the rumen and changes in ingesta specific gravity. PhD Thesis, University of Vermont.

Ehle, F. R., Bas, F., Barno, B., Martin, R. \& Leone, F. (1984). Particulate rumen turnover rate measurement as influenced by density of passage marker. Journal of Dairy Science 67, 2910-2913.

Evans, C. C., MacRae, J. C. \& Wilson, S. (1977). Determination of ruthenium and chromium by x-ray fluorescence spectrometry and the use of inert ruthenium (II) phenanthroline as a solid phase marker in sheep digestion studies. Journal of Agricultural Science, Cambridge 89, 17-22.

Evans, E. W., Pearce, G. R., Burnett, J. \& Pillinger, S. (1973). Changes in some physical characteristics of the digesta in the reticulo-rumen of cows fed once daily. British Journal of Nutrition 29, 357-376.

Faichney, G. J. \& Boston, R. C. (1983). Interpretation of the faecal excretion patterns of solute and particle markers introduced into the rumen of sheep. Journal of Agricultural Science, Cambridge 101, 575-581.

France, J., Thornley, J. H. M., Dhanoa, M. S. \& Siddons, R. C. (1985). On the mathematics of digesta flow kinetics. Journal of Theoretical Biology 113, 743-758.

Grovum, W. L. \& Williams, V. J. (1973). Rate of passage of digesta in sheep. 4. Passage of marker through the alimentary tract and the biological relevance of rate-constants derived from changes in concentration of marker in the faeces. British Journal of Nutrition 30, 313-329.

Hart, S. P. \& Polan, C. E. (1984) Simultaneous extraction and determination of ytterbium and cobalt ethylenediaminetetra-acetate complex in faeces. Journal of Dairy Science 67, 888-892.

Hooper, A. P. \& Welch, J. G. (1985). Effects of particle size and forage composition on functional specific gravity. Journal of Dairy Science 68, 1181-1188.

Kennedy, P. M., John, A., McSweeney, C. S., Murphy, M. R. \& Schlink, A. C. (1987). Comparative nutrition of cattle and swamp buffaloes given a rice straw-based diet. 2. Rumination and passage from the rumen. In Herbivore Nutrition Research, pp. 167-168 [M. Rose, editor]. Brisbane: Australian Society of Animal Production.

King, K. W. \& Moore, W. E. C. (1957). Density and size as factors affecting passage rate of ingesta in the bovine and human digestive tracts. Journal of Dairy Science 40, 528-536.

McSweeney, C. S. \& Kennedy, P. M. (1987). Comparative nutrition of cattle and swamp buffaloes given a rice straw-based diet. 3. Forestomach motility. In Herbivore Nutrition Research, pp. 169-170. [M. Rose, editor]. Brisbane: Australian Society of Animal Production.

Mader, T. L., Teeter, R. G. \& Horn, G. W. (1984). Comparison of forage labeling techniques for conduction of passage rate studies. Journal of Animal Science 58, 208-212.

Penning, P. D. (1983). A technique to record automatically some aspects of grazing and ruminating behaviour in sheep. Grass and Forage Science 38, 89-96.

Poncet, C. \& Al Abd, A. (1984). Particulate and fluid passage studies in sheep fed a hay-based diet. Canadian Journal of Animal Science 64, Suppl., 77-79.

Ralston, M. (1979). In PAR In BMDP-79: Biomedical Computer Programs, P series, pp. 484-498 [W. J. Dixon and M. B. Brown, editors]. Berkeley: University of California Press.

Reid, C. S. W. (1984). The progress of solid feed residues through the rumino-reticulum: the ins and outs of particles. In Ruminant Physiology, pp. 79-84 [S. K. Baker, J. M. Gawthorne, J. B. Mackintosh, and D. B. Purser, editors]. Perth: University of Western Australia.

Siciliano-Jones, J. \& Murphy, M. R. (1986). Passage of inert particles varying in length and specific gravity through the postruminal digestive tract of steers. Journal of Dairy Science 69, 23042311.

Siebert, B. D. \& Kennedy, P. M. (1972). The utilization of spear grass (Heteropogon contortus). I. Factors limiting intake and utilization by cattle and sheep. Australian Journal of Agricultural Research 23, 35-44. 
Smith, L. W., Erdman, R. A., Douglass, L. W. \& Slyter, L. L. (1987). Comparisons of the disappearance of ytterbium-169, chromium-51 and intrinsically carbon-14-labeled plant cell walls from continuously fed fermentors. Journal of Dairy Science 70, 576-581.

Uden, P., Colucci, P. E. \& Van Soest, P. J. (1980). Investigation of chromium, cerium and cobalt as markers in digesta. Rate of passage studies Journal of the Science of Food and Agriculture 31, 625-632.

Van Soest, P. J. \& Wine, R. H. (1967). Use of detergents in the analysis of fibrous feeds. IV. Determination of plant cell-wall constituents. Journal of the Association of Official Analytical Chemists 50, 50-55.

Warner, A. C. I. (1981). Rate of passage of digesta through the gut of mammals and birds. Nutrition Abstracts and Reviews 51, 789-820.

Welch, J. G. (1986). Physical parameters of fibre affecting passage from the rumen. Journal of Dairy Science 69 , 2750-2754.

Williams, C. H., David, D. J. \& Iismaa, O. (1962). The determination of chromic oxide in faeces samples by atomic absorption spectrophotometry. Journal of Agricultural Science, Cambridge 59, 381-385.

Wyburn, R. S. (1980). The mixing and propulsion of the stomach contents of ruminants. In Digestive Physiology and Metabolism in Ruminants, pp. 35-51 [Y. Ruckebusch and P. Thivend, editors]. Lancaster: MTP Press. 